\title{
A system for prediction of avalanche hazard in the windy climate of Iceland
}

\author{
Svanbjörg H. HARALDSDÓTTIR, ${ }^{1}$ Haraldur ÓLAFSSON, ${ }^{1}$ Yves DURAND,${ }^{2}$ \\ Gerald GIRAUD ${ }^{2}$ LaURent MÉRINDOL ${ }^{2}$ \\ ${ }^{1}$ University of Iceland and Icelandic Meteorological Office, Bústaðavegur 9, IS-150 Reykjavik, Iceland \\ E-mail:svana@vedur.is \\ ${ }^{2}$ Centre d'Études de la Neige/Météo-France, Domaine Universitaire, 1441 rue de la Piscine, 38406 Saint-Martin-d'Hères Cedex, France
}

\begin{abstract}
A system for predicting avalanche hazard in the windy climate of Vestfirðir, northwest Iceland, is presented. The system is based on (a) numerical simulations of the snowpack and evaluation of avalanche hazard due to overloading by the snow models SAFRAN-Crocus and MÉPRA, and (b) observations of wind speed in the mountains used as a proxy for snowdrift. The system was tested during two winter seasons and correctly predicts 30 out of 35 avalanche days. The 5 missing days feature either large spatial gradients in precipitation or very strong winds a few days before the avalanches, indicating much snowdrift. A comparison of the simulated avalanche hazard and observations of avalanches confirms that snowdrift is of primary importance not only for large avalanches, as already established, but also for small and medium-size avalanches in Vestfirðir. The system is a first step towards an objective evaluation of avalanche hazard in Iceland.
\end{abstract}

\section{INTRODUCTION}

In the northern part of Vestfirðir, northwest Iceland (Fig. 1), avalanches are frequent and pose a significant hazard to society. Catastrophic avalanches struck two towns in the region in January and October 1995, and 34 people perished. During the winter season, the avalanche hazard is systematically monitored and homes are evacuated in cases of critical weather and snow conditions. Avalanche forecasting at the Icelandic Meteorological Office (Veðurstofa Íslands (VÍ)) for the avalanche towns in Iceland is mostly based on subjective evaluation of weather observations, the observed build-up of the snowpack on the ground and shortrange weather forecasts. Apart from being subjective in nature, this method of avalanche forecasting has several sources of errors associated with it: point observations of the snowpack and of the weather may not be representative of the situation in the avalanche starting zones, large errors may occur in observations of solid precipitation in strong winds, and even very short-range weather forecasts can turn out to be wrong. Consequently, improved guidance for forecasting is much needed. Such a forecast guidance system that consists of objective and continuous evaluation of relevant weather parameters for avalanche forecasting is the object of this paper.

The main elements of the avalanche forecasting system are the weather-to-snowpack models SAFRAN (Système d'Analyse Fournissant des Renseignements Atmosphériques à la Neige) and Crocus (Brun and others, 1989; Durand and others, 1999) and the expert system MÉPRA (Giraud, 1993; Giraud and others, 1995, 2002) which evaluates the stability of the snowpack. The SAFRAN-Crocus-MÉPRA (SGM) models were developed for the French climate, and only SAFRAN and Crocus have been adapted to the Icelandic climate (Haraldsdóttir and others, 2001). In this study we seek to use MÉPRA's results in a novel way, whereby the days of accidental avalanche hazard showing instability of the snowpack are correlated with the days of recorded natural avalanches.

In the present study, the SCM models are used to simulate the snowpack and the avalanche hazard in north Vestfirðir during two winter seasons, 2000/01 and 2001/02. Avalanches in the region have been extensively documented, and reports from this database are compared to the model output.

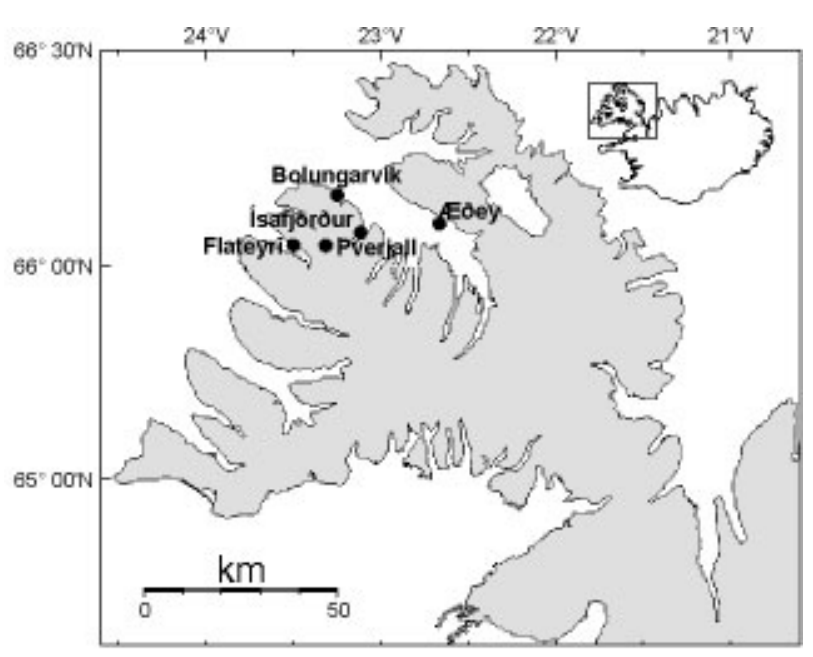

Fig. 1. Vestfirdir, northwest Iceland. 


\section{Numerical models}

The SCM models have been developed at the Snow Research Centre of Météo-France. They have been tested thoroughly in the climate of continental Europe and run daily in France on 23 Alpine and 24 Pyrenean massifs. The daily simulations in Iceland are made for 11 regions. These are of various sizes, in the range $200-600 \mathrm{~km}^{2}$ where the basic assumption is the spatial homogeneity of each region. All the numerical computations cover the whole snow season without any correction of the snowpack during the season. The snow-cover evolution depends therefore only on the analyzed meteorological conditions. The input of the models consists mainly of weather observations, in the present study from Bolungarvík, north Vestfirðir, but to some extent on objective analysis of the vertical profile of the atmosphere by the numerical weather prediction system ARPÈGE (Action Recherche Petite Échelle Grande Échelle; Courtier and others, 1991). Snowdrift is not included in the SCM models.

MÉPRA (Giraud, 1993; Giraud and others, 1995, 2002) is a physically based expert system that analyzes the characteristics of the Crocus snowpack such as shear strength, ram resistance and grain types. It evaluates the mechanical stability of the simulated snowpack and deduces a natural avalanche hazard on a six-level scale and an accidental avalanche hazard on a four-level scale. The analysis of natural avalanche hazard is based on the comparison between shear strength and shear stress in the recent or wet layers of the snowpack. Fresh snow which has fallen in calm weather usually has low shear strength and low density. The hazard is high if the depth of recent or fresh layers is $>60 \mathrm{~cm}$ (Giraud and others, 2002) with high instability, i.e. very low shear strength.

Professional forecasters use the SCM models for avalanche hazard estimation in France, in addition to other information such as field observations.

The present attempt to forecast avalanches is based on the version of the SAFRAN-Crocus models presented in Haraldsdóttir and others (2001), where the models have been adjusted to the Icelandic climate, characterized by strong winds and periods of thaw in mid-winter. Winds often blow snow past the opening of precipitation gauges, causing underestimation of precipitation amounts. The Icelandic version of the models therefore includes a precipitation correction, as well as a correction of the density of new snow due to the wind effect and local estimation of the critical temperature distinguishing between snow and rain (Ólafsson and Haraldsdóttir, 2002).

The simulations in Iceland are made for fixed altitudes, and the snow stability assessment is performed for a $40^{\circ}$ slope angle, representing the most common slopes of the starting zones. The models do not take into account smallscale features due to the local effects of wind, orography or vegetation, which is one of their main weaknesses. The results from the SCM models show both meteorological and snow conditions which include a detailed stratigraphy of all layers. In this study, the results of MÉPRA for the avalanche hazard at 400 and $600 \mathrm{~m}$ a.s.l. are used and a model avalanche day $(\mathrm{A})$ is defined if there is moderate or high hazard (3-6 on the scale for natural hazard and 3-4 for accidental hazard), and not an avalanche day $(\mathrm{N})$ if the hazard is low or very low (1-2 on both scales). A further development of the avalanche hazard estimation is then sug- gested by incorporating observed wind speeds as a proxy for snowdrift.

\section{OBSERVATIONS}

Several villages and towns in the northern part of the inhabited area in Vestfirðir (Fig. 1), as well as roads and farms, are endangered by avalanches. Bolungarvík, Flateyri and Ísafjörður are all avalanche towns. Precipitation is observed at Ísafjörður and Hnífsdalur, an avalanche village a short distance to the north of Ísafjörður. Synoptic weather observations are made at Bolungarvík and in Æðey island. Automatic wind observations are made on Pverfjall (756 m a.s.l.).

The landscape is characterized by fjords surrounded by mountains that are typically about $700 \mathrm{~m}$ high with steep slopes and that are sometimes flat on top. The area of the simulations has spatial variability such as different characters of avalanche paths, aspects and slopes, but the simulations are made for a homogeneous region.

The area is monitored by trained snow observers that record avalanches as soon as possible after they occur. In addition, qualified personnel of the road authorities record avalanches that fall on roads. For the purpose of this study, a day when avalanches are known to have struck is defined as an avalanche day.

There were 20 days with recorded avalanches in winter 2000/01, while the 2001/02 season had 15 avalanche days. None of the avalanches were larger than medium-size. During one avalanche day a maximum of 22 avalanches was recorded, and the total number of avalanches was over 157 during the two winter seasons from many avalanche paths at a distance of up to $20 \mathrm{~km}$ from Bolungarvík. Most Icelandic avalanches are slab avalanches built up of storm snow.

\section{WEATHER DURING AVALANGHE GYGLES IN NORTHWEST IGELAND}

Large avalanches in northwest Iceland are primarily associated with strong northerly winds, often associated with heavy precipitation (Jóhannesson and Jónsson, 1996; Jónsson, 1998). This is in particular true of the two most devastating avalanches in recent years, mentioned above (Ólafsdóttir, 1996; Haraldsdóttir, 1998). The most systematic attempt to link the weather as observed at weather stations in northwest Iceland to the occurrence of avalanches has been made by Björnsson (2002). Björnsson's study confirmed that there are great difficulties in predicting avalanches from the weather observed immediately before the avalanche cycle and that a simple avalanche warning system based on accumulated precipitation and maximum wind speed would lead to many more false alarms than successful avalanche predictions.

There are only small and medium-size avalanches in this study of two winters for north Vestfirðir, and the weather associated with the largest avalanche cycles is similar to that described in the literature cited above. The mean sealevel pressure for 7 days during the four most intense avalanche cycles from the two winter seasons used in this study is shown in Figure 2a. This mean field has a surface low situated at the east coast of Iceland, a surface high over Greenland and strong northeasterly flow along the east coast of 

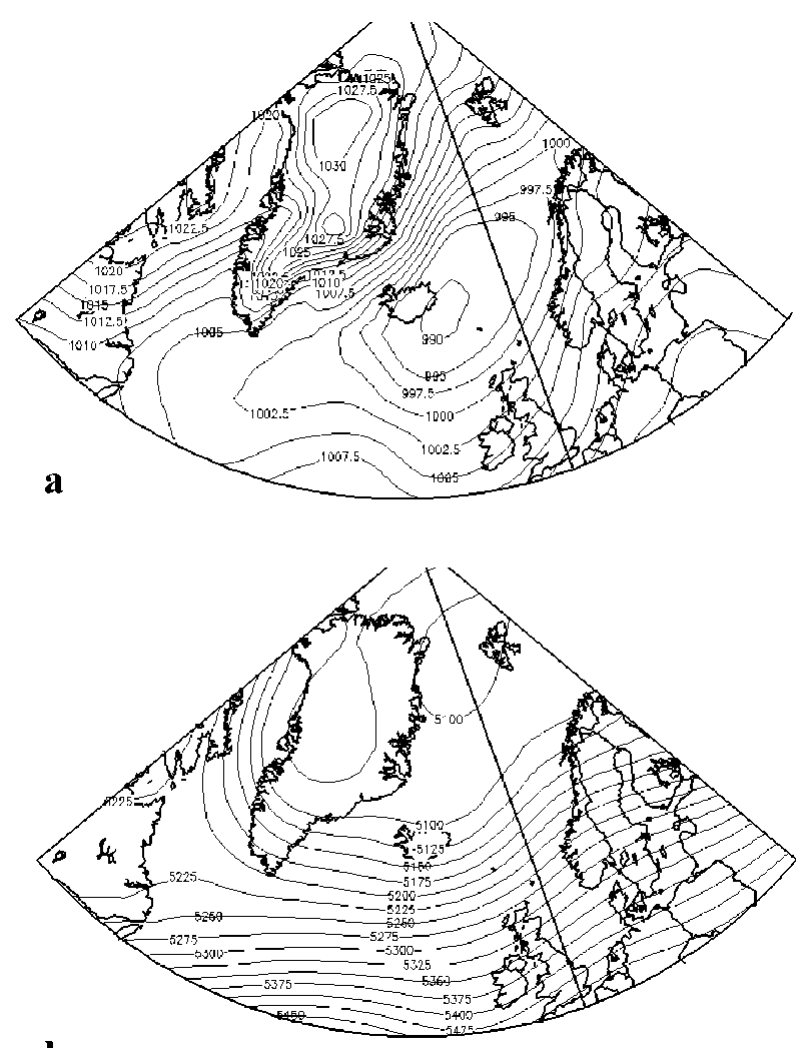

b

Fig. 2. (a) Mean sea-level pressure ( $h \mathrm{~Pa}$ ) composite mean (27-28 March 2001, 31 December 2001, 2-3 February 2002 and 21-22 February 2002). Based on the U.S. National Centers for Environmental Prediction ( NCEP) re-analysis provided by the U.S. National Oceanic and Atmospheric Administration/CIRES Climate Diagnostic Center (NOAA/CDC). (b) Mean $500 \mathrm{hPa}$ geopotential height ( $m$ ) for the same days as in (a). Based on the NCEP reanalysis provided by $N O A A / C D C$.

Greenland extending towards northwest Iceland. The corresponding $500 \mathrm{hPa}$ geopotential (Fig. 2b) shows that northwest Iceland is at the edge of the polar vortex, embedded in westerly winds that weaken rapidly to the north. With the low-level flow from the northeast and westerly flow at middle levels, the atmosphere is highly baroclinic, and there is indeed significant precipitation which is certainly enhanced locally as the strong northeasterly winds impinge on the mountains in northwest Iceland.

\section{RESULTS}

\section{Description of codes}

The results of the simulations are presented graphically in Figure 3. The winter days have been grouped into four categories. A perfect system would group all days in columns 1 and 4, i.e. NN and AA. More days in columns 2 and 3 (NA and $\mathrm{AN}$ ) indicates poorer forecast quality. A high value in column 2, NA, is of particular concern since the failure of the system to predict avalanches that occur can be catastrophic. On the other hand, if column 3, AN, is high, the system gives frequent false alarms.

\section{Natural avalanche hazard}

The first set of columns in Figure $3 \mathrm{a}$ and b shows the estimation of the natural avalanche hazard (no overloading such
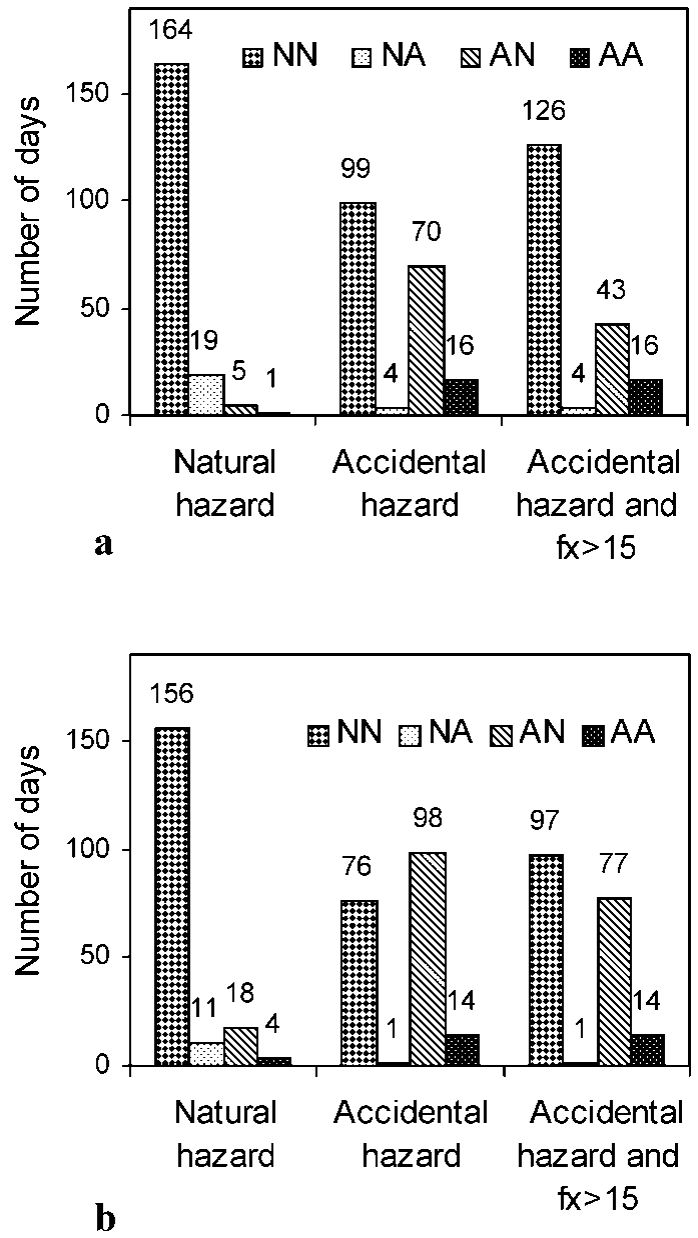

Fig. 3. The results for (a) winter 2000/01 and (b) winter 2001/02 (189 days each winter). $\mathcal{N N}=$ low model hazard, no recorded avalanches; $\mathcal{N} A=$ low model hazard, recorded avalanches; $A \mathcal{N}=$ moderate or high model hazard, no recorded avalanches; $A A=$ moderate or high model hazard, recorded avalanches.

as skiers) by the model. Here, the performance of the system is highly unsuccessful: only 1 out of 20 avalanche days is predicted in winter 2000/01, and 4 out of 15 avalanche days in winter 2001/02. In spite of few hits, the total number of false alarms (column 3) is as high as 5 and 18 days for these two winters respectively.

\section{Accidental avalanche hazard}

During days when avalanches struck, the SCM models often showed high accidental avalanche hazard, while the modelled natural avalanche hazard was low. Since avalanches tend to occur during strong winds, local overloading due to snow accumulation is strongly suspected to trigger the avalanches. The accidental avalanche hazard (hazard due to external overloading, such as skiers) is therefore a better choice in the search for an indicator for natural avalanche hazard, detecting weak layers that can fail with the additional load of accumulating snowdrift. If the overlying slab is not strong enough, an avalanche releases when a fracture or crown is formed.

An analysis of the accidental avalanche hazard presented by the second group of columns in Figure 3 gives a quite different picture. Here, 16 out of 20 avalanche days are predicted in the first season, and 14 out of 15 in the second season. On the other hand, the number of false alarms (column 3) has risen to 70 and 98 in the two seasons. 


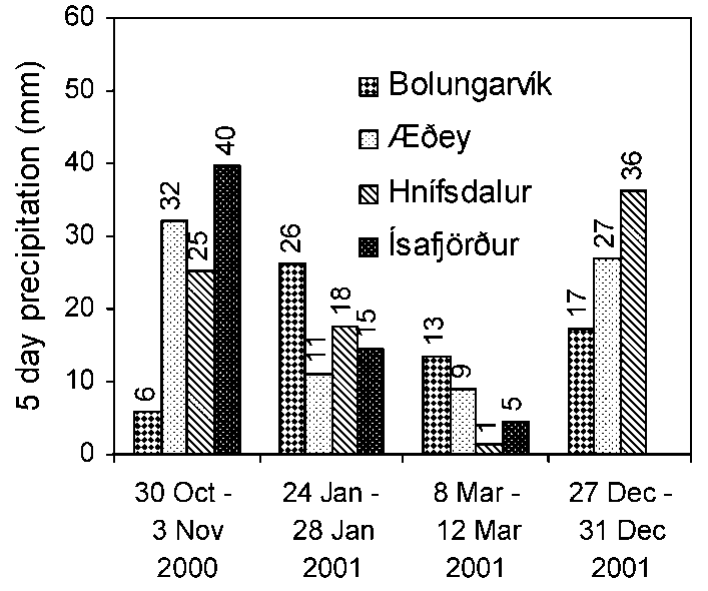

Fig. 4. Accumulated 5 day precipitation in north Vestfirdir before the avalanche days which the system missed ( $N A$ in Fig. 3). The second group is for two of the $\mathcal{N A}$ days, i.e. 27 and 28 January 2001. At Hnífsdalur the first precipitation period is 30 October-2 November 2000.

\section{Observed wind as a predictor}

It is clear that the model results for accidental avalanche hazard alone do not have a good correlation to the registered natural avalanche hazard and more predictors are needed. Bearing in mind the potential importance of the effect of snow transport by wind, the wind speed becomes a natural choice. In this study the maximum wind speed during 2 days was chosen as a predictor.

A review by Pomeroy and Gray (1995) of studies by several authors shows that the transport rate of blowing snow increases as a function of up to the fourth power of the $10 \mathrm{~m}$ wind speed. The transport rate of wind blowing at $15 \mathrm{~m} \mathrm{~s}^{-1}$ can therefore be expected to be up to five times more than at $10 \mathrm{~m} \mathrm{~s}^{-1}$. The average wind speed during 2 days may therefore not represent well the intensity of the snow transport during that time.

The average 2 day or 48 hour wind speed for the 35 avalanche days was in the range $6.2-20.8 \mathrm{~m} \mathrm{~s}^{-1}$ and averaged $12.5 \mathrm{~m} \mathrm{~s}^{-1}$. The $10 \mathrm{~min}$ maximum wind speed during 2 days, $\mathrm{fx}(2 \mathrm{~d})$, during these days always exceeded $15 \mathrm{~m} \mathrm{~s}^{-1}$. The conclusion from weather observations is that there has been snowdrift during all these periods of the two winter seasons before the avalanches struck. The maximum wind speed is a good indicator of the peak transport of snow and is therefore chosen as a predictor in our system using a criterion of $\mathrm{fx}(2 \mathrm{~d})>15 \mathrm{~m} \mathrm{~s}^{-1}$. There were two reasons for extending the period to 2 days: some of the avalanches struck in the night, in which case the wind during the previous day was probably the driving force of the snow transport, and 2 days or more of snowdrift are known to be common before avalanches strike.

In the third set of columns in Figure 3, there are two criteria considered in the avalanche forecast. The models must predict accidental hazard, and the wind-speed criterion above must be valid for the winds at the automatic weather station on Pverfjall (Fig. 1). This leads to a significant reduction of false alarms, while the proportion of predicted avalanche days (30 out of 35 for both seasons) remains unchanged.

The results from the two winter seasons are presented in a contingency table (Table 1) based on Durand and others
Table 1. Contingency table of MÉPRA risk and number of days of avalanche activity 2000-02, at north Vestfirdir (Hanssen-Kuipers score $=0.75$ )

\begin{tabular}{lcc}
\hline & \multicolumn{2}{c}{$\begin{array}{c}\text { MÉPRA risk } \\
\text { Lowerate or high }\end{array}$} \\
\hline $\begin{array}{l}\text { No observed avalanche } \\
\text { Observed avalanche }\end{array}$ & 223 & 120 \\
& 5 & 30 \\
\hline
\end{tabular}

(1999). This shows the number of days when avalanches were observed and when no avalanches were observed, grouped according to results from the SCM-model-wind system. The forecasting success is assessed with the Hanssen-Kuipers score (Hanssen and Kuipers, 1965):

$$
V=\left\{\sum_{i}\left[a_{i i} / \sum_{j}\left(a_{i j}\right)\right]\right\} / 2,
$$

where $a_{i j}$ is an element of the contingency table and $V$ is the Hanssen-Kuipers score. The result is 0.75 for the two winter seasons. The corresponding Hanssen-Kuipers score for the model accidental avalanche hazard without the wind criterion is 0.68 .

\section{DISGUSSION}

MÉPRA is an expert system and has "learned" about the avalanches in France where soft-slab and powder avalanches with low shear strength are common. The poor results obtained by directly applying the model to Iceland can be expected to be related partly to the fact that in Iceland hard-slab avalanches are the most common. Wind has a major effect on the slab formation, and without inclusion of the effect of snowdrift the models cannot be expected to give realistic results in Iceland.

When the models predict accidental hazard in the above results, it is a sign of instability and often a slab formation, enough for a skier to trigger an avalanche. It is reasonable to consider that such an instability may lead to avalanches if overloading by snow accumulation is present. The extra loading causes the underlying weak layer to fail and finally collapse which can lead to a fracture in the slab. Including a proxy for snowdrift with the accidental hazard is therefore quite reasonable.

During the two winter seasons, five days are defined as avalanche days, while our simulation system does not detect sufficient instability in the snowpack for accidental avalanche hazard. These days were as follows: on 3 November 2000, four avalanches struck at Flateyri; on 27 and 28 January 2001 three avalanches struck at Flateyri; on 12 March 2001 two avalanches struck in the Ísafjörður area; and on 31 December 2001 several avalanches blocked roads where they are cut into steep cliffs or mountainsides. A closer look at these cases reveals that on two of the days, the first and the last one, there were only a few $\mathrm{cm}$ of snow in the models, indicating that both the observed and the modelled precipitation were not representative of the precipitation in the avalanche starting zones. This is confirmed by inspection of precipitation data from locations in the vicinity of Bolungarvík (Fig. 4). So far, these data are not available for realtime simulations. The other three days had avalanche haz- 


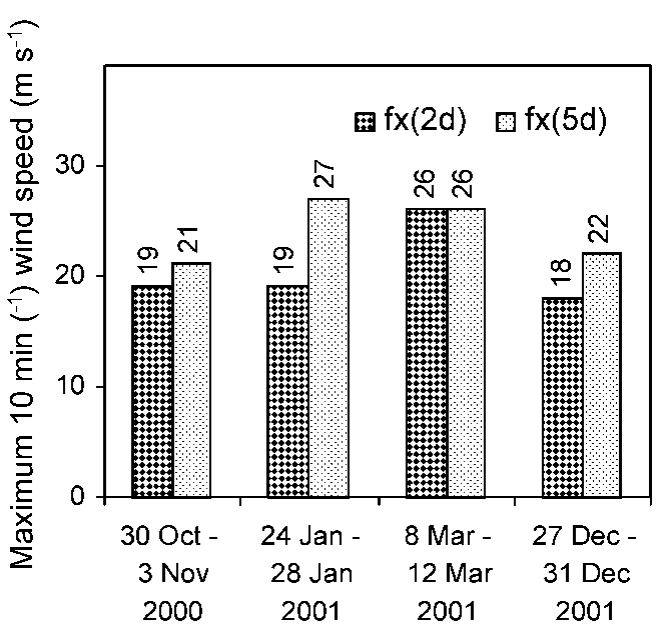

Fig. 5. The maximum 10 min wind speed for 2 days, $f x(2 d)$, and 5 days, $f x(5 d)$, at Dverfjall before the avalanche days which the models missed ( NA in Fig. 3).

ard just below the critical limits, and maximum 5 day winds $>25 \mathrm{~m} \mathrm{~s}^{-1}$, indicating potential extreme transport of snow (Fig. 5).

Even with the $15 \mathrm{~m} \mathrm{~s}^{-1}$ wind criterion, there is a large number of days with a predicted avalanche hazard but no recorded avalanches (Fig. 3, column 3 in the third set of columns). There may be at least three reasons for this high number of false alarms. The first may be associated with the fact that the rules are set for accidental avalanche hazard, i.e. avalanches can be triggered by skiers while the snowdrift overload is not sufficient to break the weak layer detected by MÉPRA. The second possible reason is that results for natural avalanche hazard should normally show avalanche hazard up to several days in a row, while the avalanches may only be recorded on one of the days. This reflects the nature of the avalanche hazard: the snowpack is unstable for several days before it stabilizes. The third reason is that avalanches may occur without being detected, or they may be detected and recorded up to 2 days after they occur.

At VÍ the main concern is that homes be evacuated in case of severe avalanche hazard. The warning system is supposed to be used as a guiding tool, and false alarms can be acceptable, but not loss of life due to NA days, i.e. no model hazard and consequently homes are not evacuated. The economic effects of evacuation of houses are hard to estimate, and the cost of misclassification such as in Blattenberger and Fowles (1995) has therefore not been considered.

The absence of predicted natural hazard during almost all the avalanche days during the two seasons supports the hypothesis that snowdrift rather than intense precipitation is the key meteorological factor causing avalanches up to medium size in north Vestfirðir. This is therefore not only true in extreme cases, as already known, but also in more typical avalanche cycles of which there are several each year. The relatively good performance of the system is based on mountain-wind observations on the same day as, and the day before, the avalanches occur, indicating that very recent snowdrift causing additional snow accumulation in the starting zones is important in producing the overloading leading to the small to medium-size avalanches. Snow accumulation in snowstorms lasting for several days is, on the other hand, known to cause catastrophic avalanches in Iceland.

\section{APPLIGATION OF OPERATIONAL AVALANGHE PREDICTION}

Currently, prediction of avalanche hazard in Iceland is mainly based on subjective evaluation of snow observations in addition to observed and predicted weather. The criteria developed here provide an objective system that can in the future serve as a first guidance for avalanche forecasting. The system predicts 30 out of 35 avalanche days in the surroundings of Bolungarvík, and the failure of the system for the remaining 5 days is easily explained either by observed precipitation not being representative of the precipitation in the avalanche starting zones or by extreme snowdrift. The system produces a number of false alarms, but that is in the nature of avalanche hazard: avalanches may be recorded as all having fallen on a single day, while the true avalanche hazard has been very high for up to several days.

As well as heavy precipitation, strong winds have been a key criterion for predicting avalanches in north Vestfirðir. It is therefore a valid question whether the SCM--wind-based system is more useful than wind-based forecasting alone. Employing only the criterion of maximum wind speed $>15 \mathrm{~m} \mathrm{~s}^{-1}$ would lead to 131 days of avalanche hazard in the 2000/01 season and 158 days in the 2001/02 season. In other words, there are about ten false alarms for every correct avalanche prediction. Such a warning system is practically useless. The corresponding ratio of our system is four to one, which, although high, is acceptable in view of the nature of the avalanche hazard.

\section{FURTHER DEVELOPMENT}

The problem of spatial variation of precipitation is a source of two out of five failures of the avalanche warning system presented in this paper. This problem will be addressed by high-resolution numerical simulations of the atmosphere. If sufficiently accurate, such simulations may provide precipitation estimations that are better than point observations, not only because of large spatial gradients in precipitation, but also due to inaccuracy in observations of solid precipitation in strong winds.

The importance of snowdrift in causing avalanche hazard in north Vestfirðir has been confirmed, and future development of the avalanche warning system will seek to account for the transport and accumulation of snow in the starting zones. A central tool in performing this task will be the newly developed snowdrift model SYTRON, described by Durand and others (2001, 2004), which will simulate the build-up of the snowpack in starting zones with respect to their aspects by transporting snow from the upstream side of a mountain over to the lee side. Not only will it provide an indicator of avalanche hazard as the current system does, but it will also help estimate the risk of extreme avalanches, which is a major concern for the evacuation services.

\section{ACKNOWLEDGEMENTS}

We are grateful to the editor, B. Jamieson, and two anonymous reviewers whose helpful comments and excellent advice improved the paper. L. Tracy helped with the language. The cooperation in the French-Icelandic team has been very good and pleasant. The Icelandic avalanche fund supported the project. 


\section{REFERENCES}

Björnsson, H. 2002. Veður i aðdraganda snjóflóðahrina á norðanverðum Vestfjörðum. Reykjavík, Veðurstofa Íslands. (VÍ-02019.)

Blattenberger, G. and R. Fowles. 1995. The road closure decision in Little Cottonwood Canyon. In ISSW'94. International Snow Science Workshop, 30 October-3 November 1994, Snowbird, Utah. Proceedings. Snowbird, UT, P.O. Box 49, 537-547.

Brun, E., E. Martin, V. Simon, C. Gendre and C. Coléou. 1989. An energy and mass model of snow cover suitable for operational avalanche forecasting. 7. Glaciol., 35(121), 333-342.

Courtier, P., C. Freydier, J.-F. Geleyn, F. Rabier and M. Rochas. 1991. The Arpège project at Météo-France. In ECMWF Seminar Proceedings, September 9-13 1991, Reading, U.K.Vol.2. Reading, European Centre for MediumRange Weather Forecasts, 193-232.

Durand, Y., G. Giraud, E. Brun, L. Mérindol and E. Martin. 1999. A computer-based system simulating snowpack structures as a tool for regional avalanche forecasting. F. Glaciol., 45(151), 469-484. (Erratum: 46(152), 2000, p. 173.)

Durand, Y., G. Guyomarc'h and L. Mérindol. 2001. Numerical experiments of wind transport over a mountainous instrumented site: I. Regional scale. Ann. Glaciol., 32, 187-194.

Durand, Y., G. Guyomarc'h, L. Mérindol and J.G. Corripio. 2004. 2D numerical modelling of surface wind velocity and associated snow drift effects over complex mountainous orography. Ann. Glaciol., 38 (see paper in this volume).

Giraud, G. 1993. MEPRA: an expert system for avalanche risk forecasting. In Armstrong, R., ed. ISSW'92. A merging of theory and practice. International Snow Science Workshop, 4-8 October 1992, Breckenridge, Colorado. Proceedings. Denver, CO, Avalanche Information Center, 97-104.

Giraud, G. and J.-P. Navarre. 1995. MEPRA et le risque de déclenchement accidentel d'avalanches. In Proceedings of the International symposium: Science and mountain - The contribution of scientific research to snow, ice and avalanche safety. ANENA, 30 May-3 June 1995, Chamonix, France, 145-150.

Giraud, G., J.-P. Navarre and C. Coléou. 2002. Estimation du risque avalancheux dans le système expert MEPRA. Grenoble, Météo-France. Centre d'Études de la Neige. (Note de Centre 20.)

Hanssen, A. W. and W. J. Kuipers. 1965. On the relationship between the frequency of rain and various meteorological parameters. Koninklijk Nederlands Meteorologisch Instituut. Mededelingen en Verhandelingen, 81, 2-15.

Haraldsdóttir, S. H. 1998. The avalanche at Flateyri, Iceland October 26th 1995 and the avalanche history. In Hestnes, E., ed. 25 Years of Snow Avalanche Research, Voss 12-16 May 1998. Proceedings. Oslo, Norwegian Geotechnical Institute, 122-127. (NGI Publication 203.)

Haraldsdóttir, S.H., H. Ólafsson, Y. Durand, L. Mérindol and G. Giraud. 2001. SAFRAN-Crocus snow simulations in an unstable and windy climate. Ann. Glaciol., 32, 339-344.

Jóhannesson, T. and T. Jónsson. 1996. Weather in Vestfirđir before and during several avalanche cycles in the period 1949 to 1995. Reykjavík, Veðurstofa Íslands (Icelandic Meteorological Office). (Technical Report G98013-ÚR15.)

Jónsson, T. 1998. Hlutfallslikur snjóflóðaátta á Vestfjörðum og á Austfjörðum. Reykjavík, Veðurstofa Íslands (Icelandic Meteorological Office). (Technical Report G98013-ÚR10.)

Óafsdóttir, U. 1996. Lavinen i Súðavik den 16, Januari 1995. Polarfront, $23(89), 12-15$.

Ólafsson, H. and S. H. Haraldsdóttir. 2002. Diurnal, seasonal, and geographical variability of air temperature limits of snow and rain. In International Conference on Alpine Meteorology (ICAM 2003), 19-23 May 2003, Brig, Switzerland. Extended abstracts. Zürich, MeteoSwiss, 473-476.

Pomeroy, J.W. and D. M. Gray. 1995. Snowcover: accumulation, relocation and management. Saskatoon, Sask., Environment Canada. National Hydrology Research Institute. (NHRI Science Report 7.) 